\title{
The Relationship between Cyber Security and Decision Support Systems
}

\author{
Ahmet Naci Unal \\ Faculty of Engineering and Natural Sciences, Bahcesehir University \\ Ciragan, Osmanpasa Mektebi St. No.4-6 Besiktas, Istanbul 34353, Turkey \\ E-mail: ahmetnaci.unal@vs.bau.edu.tr
}

\begin{abstract}
The concept of decision making is the product of a process. This process starts with defining the problem and determining the objectives. The Objectives should be practical, feasible, identifiable and compatible with the latest technology. After defining the objectives, the options for problem solving are determined. The options should consist of at least two or more variables. The next step is to determine the most optimal option. During this process, the decision maker may face various challenges. For example, the best option may not be obvious. Therefore, analytical methods should be used at this stage. However, this stage is not sufficient enough for the success of the decision process. It is necessary to implement the determined decision.

When you think that such a gradual process is used to make complex decisions, there is a need for auxiliary systems. Information technologies are used at this point. These technologies also lead us to Decision Support Systems. The fact that the decision support systems are internet open systems, it reveals the concept of cyber security.
\end{abstract}

Keywords: Decision Support Systems, Management Information Systems, Cyberspace, Cyber Security

DOI: $10.7176 / J S T R / 5-2-04$

\section{Introduction}

In our day, information is regarded as the ideational product obtained as the result of processes such as thinking, judging and reasoning. This product is attained in the end of a comprehensive process. In today's world, the said process does not have influence only on a single field but positively affects also other scientific disciplines along with it. In consequence of these interdisciplinary studies, the terms informatics or information technologies are used as the common name of computer, microelectronic and communication technologies and manages to bring together fields of science that are different than each other but also related in terms of their results such as sociology, psychology, economics, international relations and management.

With the effective use of information technologies, data quantity and the rates of data production and data access also manifest a significant increase. This increase gives prominence to concepts related with the user of the data, such as the minimization of human error, confidence in the reliability of the accessed information, and the up-to-date status of the produced information.

In an environment with such intense levels of data flow, information intensity and use, it becomes harder to make any kind of decision and decision making processes become complicated. In such an environment, helping the decision maker to make the most effective and meaningful decision emerges as a crucial need. This need brings information technologies and management sciences together and sets forth the concept of Decision Support Systems (DSS).

\section{The concept of decision making and decision support systems}

Decision making is a process human has to use regardless of his or her age, position or level of knowledge. In order for this process to occur, there has to be a problem, the solution of the problem has to be needed, the problem has to have an optional solution and there has to be a decision maker or decision makers Harrison (1995). The literature includes several definitions of decision making. What these definitions have in common is the selection of the most suitable alternative among a series of determined alternatives, and the implementation of the selected alternative. On the other hand, the common features of the concept of decision are the presence of one or more decision makers, who have an objective, the

31 | P a g e

www.iiste.org 
availability of multiple alternatives that may lead to the achievement of the objective, the set of alternatives consisting of criteria and the availability of a systematic selection method Yarman and Ünal (2015). The factors that affect the process of decision making consist of personal factors such as excitement, fears and anxiety, administrative factors such as leadership, coordination and control, and environmental factors such as the effective regulations and social and economic status Holsapple (2008). These factors are followed by the time, timing and the implementation of the made decision Forgionne (2000). The six-step decision making process set forth by Harrison (1995) is presented in Figure 1.



Fig. 1. The decision-making process

The process of decision making starts with the determination of the objectives. Besides forming the foundation of decision making, the objectives need to be practical, applicable, definable, comprehensible, open, balanced, flexible (compatible with the current state of technology), attainable within a limited period of time and suitable to improve and develop the system.

Alternatives arise as a result of situation analysis and data collection. By means of the criteria derived from the objectives, the alternatives are evaluated. The evaluation includes an anticipation of the likely outcome for each alternative.

The act of choice by itself is not the whole of the process and it is made in line with the alternative that would most likely lead the decision maker to his or her objective.

The implementation of the decision is of critical importance. This is because the fact that since a decision that is not implemented is nothing but imagination, the success of the decision cannot be talked of.

The follow-up and control step is essential to determine whether the objectives are achieved and to measure the performance. Any deviations from the standard practices have to be exposed in a timely manner and corrective actions have to be determined. Corrective actions may require the implementation of another alternative and -in case that success could not be achieved by this new alternative- the revision of the objectives Harrison (1995).

Considering the level the current technology has reached shows that decision making processes take place in complex environments and that the information intensity concerning the alternatives to be formed increases. Adding the criterion of time on top of all these eventually decreases the expected utility from the decision making process. People tend to make a more objective evaluation far from biases. At this point, the simulation of the real environment, or in other words, formation of the related mathematical model emerges as an important phenomenon. Figure 2 presents a simple process of mathematical model creation.

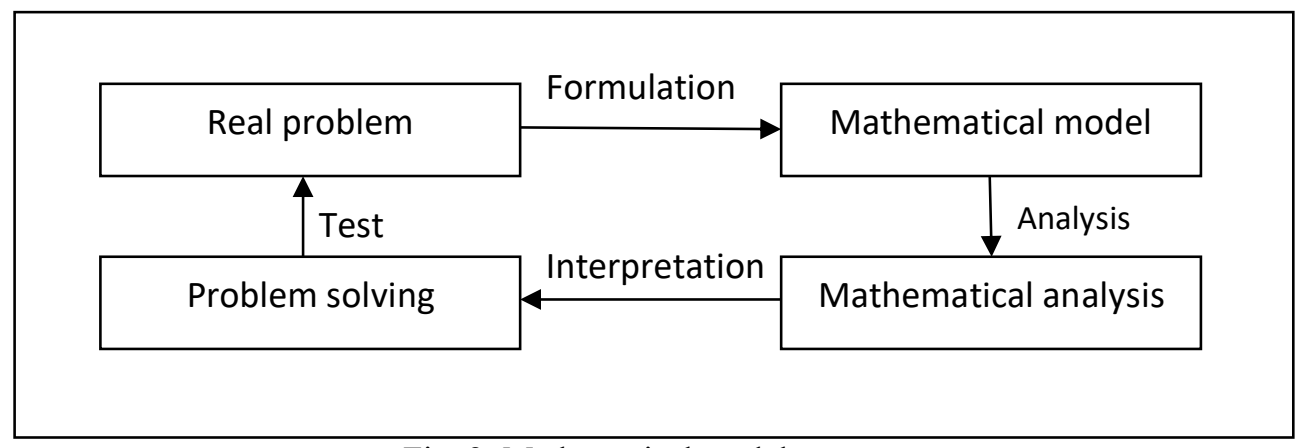

Fig. 2. Mathematical model process

32 | P a g e 
In this process, a model of the actual problem that needs to be solved is created by means of mathematical equations, mathematical solutions are obtained through the analysis of the created model, the solutions are interpreted and it is implemented and tested on the real problem. Due to the fact that this whole process requires a comprehensive mathematical background and in order to be able to finalize the process in a short period of time, information systems are utilized along with user interface. These information systems are referred as Decision Support Systems (DSS). DSS are technologies that set forth correct information with proper presentations for the correct decisions, at the right time, in a cost-effective way.

- DSS is a management support system. Its focus is the performance of situation analysis.

- DSS are systems that only supports decision making. They do not make decisions by themselves. They offer options to the decision makers and thus they maintain the decision makers' superiority.

- DSS effectively uses databases. For this, they need database management systems.

- Although DSS are usually directed at solving semi-structural problems, they are used in almost all management levels Janakiraman and Sarukesi (2008).

- DSS can be designed in data-based, model-based, information-based, document-based and communication-based forms or in real-time. Although these systems are more effective in the decisions to be made by midlevel managers, they also improve the awareness level of high-level managers. This type of DSS has six capabilities Power (2011).

- Following up whether data has been collected and stored and sending warnings to the decision makers.

- Conveying rapid changes and transformation of data to the systems and decision makers.

- Informing the decision maker when any change in the internal or external environment of the organization.

- Collecting, storing and processing new data while events take place.

- Providing instantaneous information or analyses when needed.

- Establishing compatibility between the form of the data when it was collected from the source and its usable form.

Examining these capabilities show that this type of DSS work simultaneously and utilize cyber space facilities.

\section{Decision support systems and cyberspace}

Having effectively utilized the dimensions of land and sea until the 20th Century, human also added the dimensions of air and space to his areas of interest with the start of the 20th Century. By means of the internet and information technologies it has started to use by the end of the Century, human has reached the "Cyber Space" dimension. Cyber space is a virtual environment formed by objects that can communicate with each other by using the internet base. Being referred as the fifth dimension among the areas of interest of humanity, cyber space became an environment where people utilizing the modern technology can carry out all sorts of activities. Similar to the normal space dimension, this dimension of cyber space is formed of an immense virtual environment. By November 2015, the number of people accessing cyber space through the internet is around 3.5 billion (internetworldstats-2016). In the near future, the number of cyber space-based objects that can communicate with each other is expected to reach 5 trillion.

Considering the design forms of DSS mentioned above shows that nearly all of them are cyber space based. In the solution of complex problems in a certain area of the cyber space, processed information, or in other words information as the primary material used in making decisions gains prominence along with the experiences and skills of the decision makers Yarman and Ünal (2015).

Considering the systems used on individual-, society- and even country-basis in today's world, and the information used by these systems brings along a concept that we will be referring to as critical infrastructure.

In the National Cyber Security Strategy and 2013-2014 Action Plan the critical infrastructure in Turkey are defined as "infrastructure that host information systems that may cause loss of life, large scale economic damages, national security flaws or the collapse of the public order if the confidentiality, integrity or accessibility of the processed information is disrupted" (resmigazete-2016).

Evaluating this definition manifests that almost all of the critical infrastructure systems such as energy, food, defense, public order, etc. are controlled by information systems. This, in turn, renders all these elements a component of the cyber space and ensuring the security of these facilities brings forth a special concept as cyber security. 


\section{Cyber Security}

The objective in cyber security is the protection of "information". Also with the effect of the developing technology, information enables the correct and rapid identification of the data/information we are interested in, among very large masses of data/information, the performance of the analysis/synthesis of the identified data with a high level of accuracy and the dissemination of the new information obtained as a result. As this process of generating new information shortens, the process of technologic development and the cost for reaching this technology also improve. (Ünal, 2015). And for the continuity of this positive process, information has to be secured. Securing the information depends on the accessibility, integrity, confidentiality, authentication and undeniability of the information Ünver at all (2009).

\subsection{Accessibility}

This indicates the state when all information systems are accessible, ready to use and fully functional whenever they are needed, even in undesired cases such as system errors, unexpected incidents and malicious attacks.

\subsection{Integrity}

This indicates that state where the data sent, received or stored by information system are full and unaltered.

\subsection{Confidentiality}

This indicates that the data sent, received or stored among information systems are protected against unauthorized access.

\subsection{Authentication}

Indicates the authentication of the identification information declared by the real or legal persons that use the information system.

\subsection{Undeniability}

While it indicates the provableness of any work or transaction carried out in the information system, it can also be considered with accountability, traceability and in some cases auditability.

It should be also kept in mind that while ensuring information security one can become a cyber target. In this context, in order for cyber space environments to become a target, also the sources that threaten these environments have to be identified. In consequence of this identification, it is possible to divide the sources of threat into two groups as software-based and human-based threats. Software-based threats can be classified as malicious software such as phishing software, zombie software, spam e-mail software, viruses, Trojan horses and worms. Human-based threats on the other hand take place when the crimes in the physical world are carried out by humans by using the cyber space. In short, cyber threat sources consist of humans supported by software and again target humans (Ünal and Yarman (2014).

\section{Conclusion}

Software-supported virtual environments that have become an indispensible part of our life along with the smart phones, tablets and cyber-based systems provided by today's technology, have also transformed our perception of security and set forth the concept of cyber security. By also changing dimension in threat identification, this transformation has also started to affect the society and state organizations by means of the smart networks such as websites, social networks, critical infrastructure facilities, e-state, e-banking and e-health facilities. This effect covers all layers of the society at varying levels (age, education, manager, employee, etc). The fact that the scope is that wide and effective requires the establishment of cyber security awareness in all layers of the society. Therefore, ensuring the following measures are taken is considered to be crucial:

- Cyber security strategy and application plans should be flexible and have scientific foresight in a way to adapt to all kinds of threat perception.

- The construction of the cyber security shield to be established should be formed of internal, inter-enterprise and super-enterprise layers, which should be in live interaction with each other and organized to be able to react rapidly.

- The regulation on cyber security should closely monitor the developing information technology, should be structured at both national and international levels, should cover preventive measures and observe personal rights and freedom, and should be kept up to date. 
- All necessary software and particularly those of critical infrastructure should be designed by using national source codes and in line with software design standards.

- Trainings oriented to create cyber security awareness and cyber security consciousness in all layers of the society should be designed and implemented.

- An interactive "Cyber Security Training Program" should be implemented in a well-disciplined way that would cover all layers of the society and that would create Cyber Security consciousness in the society.

\section{References}

Forgionne, G., A. (2000). Decision-Making Support Systems Effectiveness: the Process to Outcome Link. Information Knowledge Systems Management. Vol.2. Issue 2. 169-188.

Harrison, E., F. (1995). The Managerial Decision Making Process. 4th ed., Houghton Mifflin Company, Boston, 36-67.

Holsapple, C., W. (2008). Decisions and Knowledge. (Edt. Frada Burstein \& Clyde W. Holsapple). Handbooks on Decision Support Systems 1:Basic Themes, Springer, Berlin. 21-54.

http://www.internetworldstats.com/stats.htm [15.01.2019]

http://www.resmigazete.gov.tr/main.aspx?home=http://www.resmigazete.gov.tr/eskiler/2013/06/201 30620-1.htm/20130620.htm\&main=http://www.resmigazete.gov.tr/eskiler/2013/06/201306201.htm [15.01.2019]

Janakiraman, V.,S. \& Sarukesi, K. (2008). Decision Support Systems. (6.b.). New Delhi: PrenticeHall of India Private Limited, 26.

Power, D.,J. (2011). Challanges of Real-Time Decision Support. (Edt. Frada Burstein, Patrick Brezillon \& Arkady Zaslavsky). Supporting Real Time DecisionMaking: The Role of Context in Decision Support on the Move. NewYork, Springer Science+Business Media, 3-11.

Ünal, A.,N.(2015), Siber Güvenlik ve Elektronik Bileşenleri. Nobel Akademik Yayıncılı, Ankara. 105-116.

Ünver, M., Canbay, C. \& Mirzaoğlu A., G., Siber Güvenliğin Sağlanması: Türkiye'deki Mevcut Durum ve Alınması Gereken Tedbirler. Bilgi Teknolojileri ve Koordinasyon Dairesi Başkanlığ1, Mayıs 2009. http://www.cybersecurity.gov.tr/publications/sg.pdf [20.06.2014].

Yarman,B.,S.,B. \& Ünal, A., N.(2015), Stratejik Karar Verme Boyutunda Bilgi Toplama/Işsleme Amaçlı Karar Destek Sistemleri. Nobel Akademik Yayıncılık, Ankara, 2015. 11-18. 